\title{
Phage-Host Specificity Tests using Levinea Phages and Isolates of Levinea spp. and Citrobacter freundii
}

\author{
DAIEL E. MARKEL, ${ }^{1}$ MARY JO FOWLER, AND CURTIS EKLUND \\ Department of Biological Sciences, University of Texas at El Paso, El Paso, Texas 79968, and Texas State \\ Health Department, Austin, Txas 78756
}

\begin{abstract}
Phage-host specificity tests were accomplished utilizing six serologically unrelated phages with 177 isolates of the genus Levinea and 44 Citrobacter freundii isolates. A total of $84 \%$ of the levineae were infected by at least one of the phages, and 21 phage-host patterns were obtained. Only $9 \%$ of the $C^{\prime}$. freundii isolates were infected. One phage, DM-21, only infected L. malonatica whereas the other phages showed no species specificity. Most of the infectivity patterns were specific for either $L$. amalonatica or $L$. malonatica, but some patterns showed no host specificity. A correlation was found between dulcitol fermentation and infectivity with DM-21. There was no evidence of a relationship between infectivity and source of isolation. The recommendation that the proposed genus Levinea be accepted rather than the inclusion of these organisms within the genus Citrobacter is discussed.
\end{abstract}

With the dichotomy which exists as to the classification of the Levinea organisms, a unique opportunity arose to utilize the Levinea phages isolated by Markel and Eklund $(7,7 \mathrm{a})$ as a taxonomic tool to demonstrate whether a relatedness existed between the genera Levinea and Citrobacter. Major biochemical and serological differences between the two genera have been described and discussed previously $(7,12)$. It is apparent that these organisms are being isolated more frequently in the United States $(1,6,9,10)$ and abroad $(5,8,13)$ in clinical laboratories, and the need for an agreement on nomenclature is obvious.

The purpose of this study was to test both Levinea and Citrobacter isolates for infectivity by the Levinea phages. The possible use of the phage infectivity patterns for species identification of Levinea was examined. Correlation between phage infectivity and the hosts' biochemical reactions was also investigated. (This investigation was presented in part at the March 1974 meeting of the Texas Branch of the American Society for Microbiology, Houston, Texas.)

Bacterial cultures. From July 1968 to January 1974, the Texas State Health Department (TSHD) at Austin, Texas, accumulated 285 enteric isolates which were qualified to be classified in the genus Levinea on the basis of key biochemical reactions. From these, 173 were randomly selected for use in phage susceptibil-

' Present address: Department of Microbiology, The University of Texas Medical Branch, Galveston, Tex. 77550. ity tests. There were 57 cultures of Levinea amalonatica, 108 cultures of Levinea malonatica, and 8 cultures of Levinea interme. diates. A reference strain of each $L$. amalonatica and $L$. malonatica used in the isolation of the phages DM-11, DM-21, and DM-31, as well as L. amalonatica (ATCC 25405) and L. malonatica (ATCC 25408) utilized in the isolation of DM-41, DM-51, and DM-61, was included (7, 7a). A total of 177 Levinea orgaisms were tested. Screening criteria for the genus Levinea and Citrobacter freundii are given in Table 1. Species differentiation of levinea is based on the possible combination of three biochemical reactions which are listed in Table 2 along with the corresponding reactions for Citrobacter. Also tested were 27 isolates of $\mathrm{H}_{2} \mathrm{~S}$-positive $C$. freundii and $16 \mathrm{H}_{2} \mathrm{~S}$-negative $C$. freundii variants which were randomly selected from TSHD isolates and an $\mathrm{H}_{2} \mathrm{~S}$-positive $C$. freundii strain (ATCC 8090). A total of 44 Citrobacter isolates were tested.

Phages. The six Levinea phages previously reported $(7,7 \mathrm{a})$ were used in the phage-host susceptibility tests.

Methods. The methods used in the preparation of indicator organisms and host specificity tests have been previously described (7).

Phage-host specificity tests. The percentage of the Levinea and Citrobacter organisms infected by at least one Levinea phage is presented in Table 3. None of the six phages were infective for any of the $\mathrm{H}_{2} \mathrm{~S}$-positive Citrobacter isolates and a very low percentage 
of infection was obtained for the $\mathrm{H}_{2} \mathrm{~S}$-negative Citrobacter variants. A high percentage of Levinea cultures was infected.

The host specificity tests are segregated into species infected by the individual phages in Table 4. Five of the six phages lacked species specificity; however, DM-21 appeared to be infective only for $L$. malonatica.

Phage infectivity patterns. Phage infectivity patterns of the 177 Levinea isolates are presented in Table 5. Patterns 1 to 10 were specific for $L$. malonatica whereas patterns 11 to 14 were specific for $L$. amalonatica. Six patterns showed no species specificity. One pattern included those organisms which were not infected by any of the six phages.

Correlation of phage susceptibility with the hosts' biochemical characteristics and sources of isolation. Results indicated that DM-21 was infective for 29 of $110 \mathrm{~L}$. malonatica isolates. Of these 29 organisms, $20(69 \%)$ were dulcitol positive. It was also noted that all 59 isolates of $L$. amalonatica were dulcitol negative and were not infected by DM-21. No one infectivity pattern was specific for the dulcitol fermentation; however, $45 \%$ of the infected organisms had a pattern consistent with number 6 in Table 5 . There was no apparent correlation between source of the isolates and phage infectivity patterns.

Phages are usually host specific in that their infectivity has been restricted to closely related species of a single genus. However, this specificity is not always observed in the genera included

TABLE 1. Biochemical screening criteria for Levinea with corresponding reactions for $C$. freundii

\begin{tabular}{l|c|c}
\multicolumn{1}{c|}{ Biochemical reactions } & Levinea & C.freundii \\
\hline Triple sugar iron agar & Acid butt, & Acid butt, \\
& $\mathrm{H}_{2} \mathrm{~S}-$ & $\mathrm{H}_{2} \mathrm{~S}+$ \\
Indole & + & - \\
Methyl red & + & + \\
Simmons' citrate & + & + \\
Phenylalanine deaminase & - & - \\
Lysine decarboxylase & - & - \\
Ornithine decarboxylase & + & - \\
\hline
\end{tabular}

in the family Enterobacteriaceae. Some phages have been isolated that can infect more than one host genus. These observations have been postulated to be due to the fact that this family contains separate genera that are closely related but differ in certain key biochemical reactions (2).

The opportunity to utilize the Levinea phages as taxonomic tools to yield evidence as to the classification of levineae has been obvious. If these phages showed a high infectivity for the typical $C$. freundii, then the contention of Ewing and Davis that the organisms are to be classified as Citrobacter would be apparent and justified (4). As the results indicated, such was not the case. There was no infectivity for the typical $\mathrm{H}_{2} \mathrm{~S}$-positive $\mathrm{C}$. freundii. The small number of atypical $\mathrm{H}_{2} \mathrm{~S}$-negative $C$. freundii organisms which were infected was not significant as compared to the high percentage of the Levinea organisms which were infected (Table 3).

Phage infectivity patterns indicated that the phages could be useful in identification of levineae since a number of patterns were specific for only one species. These patterns were reproducible when random samples were selected for retesting.

Correlation was observed between dulcitol fermentation and DM-21 infectivity. No correlation between phage infectivity and source of isolation was apparent.

TABLE 3. Number of organisms infected by at least one Levinea phage

\begin{tabular}{l|r|r|r}
\hline \multicolumn{1}{c|}{ Organism } & $\begin{array}{c}\text { No. of } \\
\text { isolates }\end{array}$ & $\begin{array}{c}\text { No. } \\
\text { infected }\end{array}$ & $\%$ \\
\hline Levinea amalonatica & 59 & 43 & 73 \\
Levinea malonatica & 110 & 99 & 90 \\
Group III & 7 & 5 & 71 \\
Group IV & 1 & 1 & 100 \\
$\quad$ Total & 177 & 148 & 84 \\
Citrobacter freundii & & & \\
H $_{2}$ S-positive & & & \\
$\mathrm{H}_{2}$ S-negative & 28 & 0 & 0 \\
$\quad$ Total & 16 & 4 & 25 \\
\hline
\end{tabular}

TABLE 2. Biochemical tests for species differentiation of Levinea

\begin{tabular}{l|c|c|c|c|c}
\hline \multicolumn{1}{c|}{ Test } & Group I & Group II & Group III & Group IV & C. freundii \\
\hline Adonitol & + & - & - & + & - \\
Malonate & + & - & + & - & - \\
KCN & - & + & Vary & Vary & + \\
Designation & L. amalonatica & L. malonatica & & & C.freundii \\
\hline
\end{tabular}


TABLE 4. Number of isolates infected by each Levinea phage

\begin{tabular}{l|c|c|c|c|r|r}
\hline & DM-11 & DM-21 & DM-31 & DM-41 & DM-51 & DM-61 \\
\hline Levinea malonatica & $\mathbf{1}$ & 30 & $\mathbf{8 1}$ & $\mathbf{5}$ & 65 & 68 \\
Levinea amalonatica & 5 & 0 & 24 & 2 & 3 & 38 \\
Group III & 0 & 0 & 4 & 0 & 5 & 4 \\
Group IV & 0 & 0 & 1 & 0 & 0 & 1 \\
Citrobacter freundii & 0 & 0 & 0 & 0 & 0 & 0 \\
$\mathrm{H}_{2}$ S positive & 0 & 0 & 1 & 0 & 0 & 4 \\
$\mathrm{H}_{2}$ S negative & & & & & \\
\hline
\end{tabular}

TABLE 5. Phage-host infectivity patterns

\begin{tabular}{c|c|c|c|c|c|c|c|l}
\hline Pattern & DM-11 & DM-21 & DM-31 & DM-41 & DM-51 & DM-61 & Total \% & Organisms infected $^{a}$ \\
\hline 1. & + & + & + & + & + & + & 0.6 & L.m. \\
2. & - & + & + & + & + & + & 0.6 & L.m. \\
3. & - & + & + & + & - & + & 0.6 & L.m. \\
4. & - & + & + & - & + & - & 2.8 & L.m. \\
5. & - & + & + & - & - & - & 1.1 & L.m. \\
6. & - & + & + & - & - & + & 4.0 & L.m. \\
7. & - & + & + & - & - & - & 6.3 & L.m. \\
8. & - & + & - & - & - & - & 0.6 & L.m. \\
9. & - & - & + & + & + & + & 1.1 & L.m. \\
10. & - & - & - & - & + & + & 2.8 & L.m. \\
11. & + & - & + & - & - & + & 1.1 & L.a. \\
12. & + & - & - & - & - & + & 1.7 & L.a. \\
13. & - & - & + & + & - & - & 0.6 & L.a. \\
14. & - & - & - & + & - & + & 0.6 & L.a. \\
15. & - & - & + & - & - & - & 3.5 & L.a., L.m. \\
16. & - & - & + & - & - & - & 4.0 & L.a., L.m. \\
17. & - & - & - & - & - & + & 9.6 & L.a., L.m. \\
18. & - & - & + & - & + & + & 23.7 & L.a., L.m., Grp III \\
19. & - & - & + & - & - & + & 13.0 & L.a., L.m., Grp IV \\
20. & - & - & - & - & + & - & 6.8 & L.m., Grp III \\
21. & - & - & - & - & - & - & 15.8 & L.a., L.m., Grp III \\
\hline
\end{tabular}

${ }^{a}$ L.a., L. amalonatica; L.m., L. malonatica.

In conclusion, the authors recommend that the generic designation Levinea, as proposed by Young et al. (12) be accepted rather than placing the organisms within the genus Citrobacter for the following reasons: (i) biochemical tests have clearly demonstrated a separate genus (12); (ii) phage-host specificity tests demonstrated no relatedness between Levinea and Citrobacter; (iii) Young et al. (12) reported no serological relatedness between Levinea and Citrobacter, yet all members of the tribe Salmonellae have been reported to be serologically related (3); (iv) the addition of $C$. diversus as a second accepted species within the Citrobacter genus would necessitate revision of the genus as well as the tribe Salmonellae (4); (v) C. diversum, originally described by Werkman and Gillen (11), differs from $C$. diversus as described by Ewing and Davis (4) in that it was described as $\mathrm{H}_{2} \mathrm{~S}$ positive, gave an indefinite methyl red test, and was nonmotile. Negative
$\mathrm{H}_{2} \mathrm{~S}$ production and a positive methyl red reaction are distinctive biochemical characteristics of the genus Levinea and most isolates are motile.

\section{REPRINT REQUESTS}

Address reprint requests to: Dr. Curtis Eklund, Dept. of Biological Sciences, University of Texas at El Paso, El Paso, Tex. 79968.

\section{LITERATURE CITED}

1. Booth, E. V., and S. McDonald. 1971. A new group of enterobacteria, possibly a new Citrobacter $\mathrm{sp.}$. J. Med. Microbiol. 4:329-36.

2. Bradley, D. E. 1967. Ultrastructure of bacteriophages and bacteriocins. Bacteriol. Rev. 31:230-314.

3. Edwards, P. R., and W. H. Ewing. 1972. Identification of Enterobacteriaceae, 3rd ed. Burgess Publishing Co. Minneapolis.

4. Ewing, W. H., and B. R. Davis. 1972. Biochemical characterization of Citrobacter diversus (Burkey) Werkman and Gillen and designation of the neotype strain. Int. J. Syst. Bacteriol. 22:12-18.

5. Gross, R. J., B. Rowe, and J. A. Easton. 1973. Neonatal 
meningitis caused by Citrobacter koseri. J. Clin. Pathol. 26:138-39.

6. Jones, S. R., A. R. Ragsdale, E. Kutscher, and J. P. Sanford. 1973. Clinical and bacteriologic observations on a recently recognized species of Enterobacteriaceae, Citrobacter diversus. J. Infect. Dis. 128:563-65.

7. Markel, D. E., and C. Eklund. 1974. Isolation, characterization, and classification of three bacteriophage isolates for the genus Levinea. Int. J. Syst. Bacteriol. 24:230-34.

7a. Markel, D. E., and C. Eklund. 1975. Isolation, characterization, and classification of additional bacteriophages for the genus Levinea. Int. J. Syst. Bacteriol. 25:210-214.

8. Richard, C., B. Brisou, and J. Lioult. 1972. Etude taxonomique de Levinea, nouveau genre de la famille des Entérobactéries. Ann. Inst. Pasteur Paris 122: 1137-46.

9. Smith, R. F., S. L. Dayton, and D. D. Chips. 1973 Recognition of Citrobacter diversus in the clinical laboratory. Appl. Microbiol. 25:157-58.

10. Washington, J. A., II, P. K. W. Yu, and W. J. Martin. 1970. Hydrogen sulfide-negative variant of Citrobacter. Appl. Microbiol. 20:587-89.

11. Werkman, C. H., and G. F. Gillen. 1932. Bacteria producing trimethylene glycol. J. Bacteriol. 23:167-82.

12. Young, V. M., D. M. Kenton, B. J. Hobbs, and M. R. Moody. 1971. Levinea, a new genus of the family Enterobacteriaceae. Int. J. Syst. Bacteriol. 21:58-63.

13. Zechovsky, N., E. Bergogne-Berezin, and C. Richard. 1973. Urinary infection with Levinea malonatica. Nouv. Presse. Med. 2:584. 